\title{
Oncogenic drivers in 11q13 associated with prognosis and response to therapy in advanced oropharyngeal carcinomas
}

\author{
M.C. Barros-Filho ${ }^{\mathrm{a}, 1}$, L.A. Reis-Rosa ${ }^{\mathrm{b}, 1}$, M. Hatakeyama ${ }^{\mathrm{a}, 1}$, F.A. Marchi ${ }^{\mathrm{a}}$, T. Chulam ${ }^{\mathrm{c}}$, \\ C. Scapulatempo-Neto ${ }^{\mathrm{d}}$, U.R. Nicolau ${ }^{\mathrm{e}}$, A.L. Carvalho ${ }^{\mathrm{f}}$, C.A.L. Pinto ${ }^{g}$, S.A. Drigo ${ }^{\mathrm{h}}$, L.P. Kowalski ${ }^{\mathrm{c}, \mathrm{i}}$, \\ S.R. Rogatto ${ }^{\mathrm{i}, \mathrm{j}, *}$ \\ ${ }^{a}$ International Research Center (CIPE), A. C. Camargo Cancer Center, São Paulo, Brazil \\ b Instituto de Medicina Tropical de SP Universidade de São Paulo-USP, São Paulo, Brazil \\ ${ }^{\mathrm{c}}$ Department of Head and Neck Surgery and Otorhinolaryngology, A. C. Camargo Cancer Center, São Paulo, Brazil \\ ${ }^{\mathrm{d}}$ Molecular Oncology Research Center, Barretos, and Diagnósticos da América (DASA), São Paulo, Brazil \\ e Department of Oncology, A. C. Camargo Cancer Center, São Paulo, Brazil \\ ${ }^{\mathrm{f}}$ Department of Head and Neck Surgery, Barretos Cancer Hospital, Barretos, Brazil \\ ${ }^{g}$ Department of Pathology, A. C. Camargo Cancer Center, São Paulo, Brazil \\ ${ }^{\mathrm{h}}$ Department of Surgery and Orthopedics, School of Medicine and Department of Veterinary Clinic, School of Veterinary Medicine and Animal Science, UNESP, Botucatu, \\ Brazil \\ ${ }^{\mathrm{i}}$ National Institute of Science and Technology in Oncogenomics (INCiTO), São Paulo, Brazil \\ ${ }^{\mathbf{j}}$ Department of Clinical Genetics, Vejle Hospital, Institute of Regional Health Research, University of Southern Denmark, Denmark
}

\section{A R T I C L E I N F O}

\section{Keywords:}

Oropharyngeal cancer

Driver alterations

Human papilloma virus

Prognostic factors

Predictive factors

Transcriptome profiling

Array comparative genomic hybridization

Reverse transcriptase polymerase chain

reaction

\begin{abstract}
A B S T R A C T
Objectives: To identify potential molecular drivers associated with prognosis and response to treatment in advanced oropharyngeal squamous cell carcinomas (OPSCC).

Materials and methods: Thirty-three OPSCC biopsies from untreated Brazilian patients were evaluated for human papilloma virus genotyping, genome wide copy number alterations and gene expression profiling. Data were integrated using CONEXIC algorithm. Validation with TCGA dataset and confirmation by RT-qPCR of candidate genes were performed.

Results: High-risk HPV positive cases, detected in 55\% of advanced OPSCC, were associated with better outcome. Losses of 8p11.23-p11.22, 14q11.1-q11.2 and 15q11.2, and gains of 11q13.2 and 11q13.2-q13.3 were detected as recurrent alterations. Gains of 3q26.31 and 11q13.2 and losses of 9p21.3 were exclusively detected in HPV-negative tumors. Two clusters of expression profiles were observed, being one composed mostly by HPV positive cases (83\%). HPV-positive enriched cluster showed predominantly immune response-related pathways. Integrative analysis identified 10 modulators mapped in 11q13, which were frequently cancer-related. These 10 genes showed copy number gains, overexpression and an association with worse survival, further validated by TCGA database analyses. Overexpression of four genes (ORAOV1, CPT1A, SHANK2 and PPFIA1) evaluated by RT-qPCR confirmed their association with poor survival. Multivariate analysis showed that PPFIA1 overexpression and HPV status are independent prognostic markers. Moreover, SHANK2 overexpression was significantly associated with incomplete response to treatment.

Conclusion: The integrative genomic and transcriptomic data revealed potential driver genes mapped in 11q13 associated with worse prognosis and response to treatment, giving fundamentals for the identification of novel therapeutic targets in OPSCC.
\end{abstract}

\section{Introduction}

In the last decades, several epidemiological studies have revealed decreased incidence of head and neck squamous cell carcinomas (HNSCC) in oral cavity and larynx as a consequence of lower exposure to the tobacco products. Nevertheless, an increasing incidence of

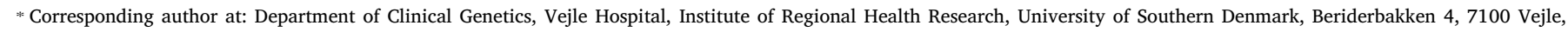
Denmark.

E-mail address: silvia.regina.rogatto@rsyd.dk (S.R. Rogatto).

${ }^{1}$ These authors contributed equally. 
oropharyngeal squamous cell carcinomas (OPSCC) mainly associated with oncogenic human papillomavirus (HPV) has been reported [1-6].

In general, HPV-positive OPSCC is associated with good prognosis, presenting better survival in comparison with HPV-negative cases [7-11]. De-escalation of radiation and chemotherapy for HPV-positive cases has been proposed and tested in different clinical trials aiming to avoid overtreatment and long-term toxicities $[8,12,13]$. However, accurate identification of cases with good prognosis and treatment-responsive tumors are critical findings, since distant metastasis may occur in a set of HPV-positive OPSCC $[8,14]$. In contrast, few advances have been made for treatment of HPV-negative OPSCC patients and a large number of them will present loco-regional recurrence [9].

The molecular mechanisms underlying oropharyngeal carcinogenesis have been investigated and potential biomarkers were reported, however the data are still unclear and controversial [15-19]. The integration of genomic and transcriptomic analysis can be used to identify cancer-driver genes and disrupted pathways, which can be drug targetable [20]. This strategy has revealed functionally relevant drivers involved in the carcinogenic process in different tumor types, including oral carcinoma [21], ovarian cancer [22], penile carcinoma [23,24], uterine leiomyoma [25] and leiomyosarcoma [26].

Integration of genomic, transcriptomic and epigenomic data of 279 HNSCC, including oral $(\mathrm{n}=172,62 \%)$, oropharyngeal $(\mathrm{n}=33,12 \%)$ and laryngeal $(n=72,26 \%)$ carcinomas was reported by The Cancer Genome Atlas (TCGA) [27]. Distinct genetic alterations were observed between HPV-positive HNSCCs (68\% in oropharynx) and HPV-negative cases. Recurrent deletions and truncating mutations of TRAF3 found in HPV-positive tumors were associated with anti-viral immune response. Conversely, HPV-negative HNSCCs presented loss of 9p21.3 (including CDKN2A gene) and co-amplifications of $11 \mathrm{q} 13$ and 11q22, which contain genes implicated in cell death/NF-kB and Hippo pathways [27]. A distinct genetic subgroup of HPV-negative tumors is also being reported, characterized by low frequency of copy number alterations (CNA), wild-type TP53, mutation in HRAS and CASP8 and more favorable prognosis [13].

Nevertheless, prognostic and predictive biomarkers in advanced OPSCC are still limited and need to be further investigated. In this study, we integrated DNA CNA and gene expression analyses to identify drivers in advanced OPSCC according to HPV status. In silico functional analysis was performed to identify genes and pathways associated with oropharyngeal carcinogenesis, which can reveal potential drug targets.

\section{Patients and methods}

\section{Patients and samples}

Fresh-frozen tumor biopsy samples from 40 OPSCC patients naive of treatment were obtained from A.C. Camargo Cancer Center and Barretos Cancer Hospital, Brazil. Eligibility criteria included patients harboring locally advanced clinical stages III, IVA and IVB according to AJCC ( $7^{\text {Th }}$ Edition). The follow-up time ranged from 0.5 to 190 months (mean of 53 months). The study was approved by the Human Research Ethics Committee from both Institutions (A.C. Camargo Cancer Center \#1249/09 and Barretos Cancer Hospital \#139/2008). All patients provided written informed consent. Patients underwent curative therapy according to standard clinical protocol taking into account the medical decisions for each patient, which included induction chemotherapy (IC) followed by radiotherapy with concurrent chemotherapy (CT-RT), and upfront surgical resection followed by radiotherapy with or without chemotherapy. Pretreatment risk stratification was defined as low, intermediate and high, based on HPV status, smoking history and tumor/node stage [7].

\section{Treatment and response assessment}

The majority of patients included in this study were treated by IC followed by CT-RT $(n=24)$. Patients were treated with a combination of docetaxel, cisplatin and 5-fluorouracil (TPF) as IC followed by radiotherapy and weekly carboplatin or cisplatin concurrent to radiotherapy. Cetuximab was employed in eight cases as concurrent therapy to radiation (one case received IC before). Six patients were treated by surgery followed by adjuvant therapy (RT or RT $+\mathrm{CT}$ ); one patient deceased surgery and one patient lost the follow-up before completing the treatment (supplementary Table S1). Six patients were treated only by surgery followed by adjuvant therapy (RT and or CT), one patient deceased soon after surgery and one patient lost the follow-up before treatment begins.

\section{Nucleic acids extraction and HPV genotyping}

OPSCC samples (80\% of tumor cells) and surrounding normal tissues were macrodissected for DNA (Qiagen DNeasy Blood \& Tissue Kit; Qiagen, Valencia, CA) and total RNA extraction (RNeasy MiniKit; Qiagen, Valencia, CA). The Linear Array HPV Genotyping Test Kit (Roche Molecular Systems, Inc., Branchburg, NJ, USA) was used for HPV detection.

\section{CNA analysis by array-based Comparative genomic Hybridization}

OPSCC ( $n=33$ ) and normal commercial DNA (Promega) samples were differentially labeled (Genomic DNA Enzymatic Labeling Kit; Agilent Technologies) and the hybridized on Agilent Human CGH 180K Oligo Microarrays. Genomic data were extracted by Feature Extraction 10.1.1.1 software (Agilent Technologies) and analyzed using the Nexus Copy Number software (v.6.0, Biodiscovery, El Segundo, CA, USA). CNA was defined as exceeding the significance threshold of $1 \times 10^{-6}$ and containing at least five consecutive altered probes per segment. The thresholds were defined as the average $\log _{2}$ CGH fluorescence ratio for copy gains $\geq 0.6$, high copy number gains $\geq 1.4$, losses $\leq-0.6$ and homozygous losses $\leq-1.25$. Genomic variants detected in control individuals from worldwide populations and classified as common (>1\%) according to DGV database (http://dgv.tcag.ca/dgv/app/ home) were excluded. Alterations detected in at least $20 \%$ of the cases were selected for further analysis. The unsupervised hierarchical clustering analysis was performed using complete linkage and Euclidian distance.

\section{Gene expression microarray}

Total RNA from OPSCC $(n=33)$ and surrounding non-neoplastic oropharyngeal tissues $(n=3)$ were labeled and hybridized using the Two-Color Human GE $4 \mathrm{x} 44 \mathrm{~K}$ microarray platform (Agilent Technologies), following the manufacturer instructions. Data processing, quality control filtering and normalization (Lowess) were performed using the Feature Extraction v.10.1.1.1 software (Agilent Technologies) and an in-house pipeline. Gene expression analysis was performed using R version 2.15 (http://www.bioconductor.org/) and BRB ArrayTools software (v.4.4.0). An unsupervised hierarchical clustering analysis was employed with the most variable probes (interquartile range $>0.1$ ) using complete linkage and Euclidian distance. Transcriptomic variations among clusters were identified by significance analysis of microarray (SAM) (false discovery ratio $<1 \%$ ).

The CNA and expression microarray data are available at the Gene Expression Omnibus (GEO) (GSE111395).

\section{Integrative analysis}

Paired CNA and gene expression data of 33 OPSCC was integrated using COpy Number and EXpression In Cancer (CONEXIC) algorithm to identify drivers, which results in a ranked list with high scores modulators [28]. In this analysis, unbalanced expressed genes are correlated with the expression of group of genes (modules), and genomic regions 
with significant alterations indicate a greater possibility of the gene has some adaptive advantage on the tumor phenotype. Parameters used in this analysis were described elsewhere [25]. Mann-Whitney test (Prismv.5.0, GraphPad Software, La Jolla, CA) was applied to analyze the relationship between gene expression and CNA.

\section{External data validation and in silico functional analysis of driver candidates}

Driver candidates were validated in 78 OPSCC available in the TCGA public database (SNP arrays and RNAseq), using cBio Cancer Genomics Portal (http://www.cbioportal.org/public-portal/index.do) assessed in February 2018). Ingenuity ${ }^{\circledR}$ Pathway Analysis (IPA v2.3; http://www.ingenuity.com) and KOBAS (v.3.0; http://kobas.cbi.pku. edu.cn/) software was additionally used to highlight enriched canonical pathways modulations.

\section{Data validation by reverse transcription quantitative polymerase chain reaction ( $R T-q P C R)$}

Thirty OPSCC (23 array-dependent and 7 independent samples) and four non-neoplastic oropharyngeal tissues were assessed to evaluate the ORAOV1, CPT1A, PPFIA1 and SHANK2 transcript levels by RT-qPCR (primer sequences are showed in supplementary Table S2). HMBS and HPRT1 were selected as reference genes using geNorm algorithm (tested in combination with ACTB, GAPDH and GUSB) [29]. Robotic pipetting was carried out using QIAgility (QIAGEN) in a total volume of 12.5 uL containing Power SYBR Green PCR Master Mix (Applied Biosystems), $20 \mathrm{ng}$ of cDNA and $200 \mathrm{nM}$ of each primer. All samples were analyzed in duplicate. Normalized relative gene expression was obtained according to Pffafl method [30].

\section{Statistical analysis}

Fisher exact test was used to associate the clustering analysis and copy number alterations with clinicopathological features. Transcript levels were evaluated according to CNA and response to therapy using Mann-Whitney test. High expression levels were defined as at least twofold in tumor tissues compared to normal tissues. Overall and diseasefree survival probabilities were calculated using Kaplan-Meyer method and statistically compared with log rank. Multivariate analysis was applied using Cox proportional hazards including all variables with $p$ value $<0.1$ in the univariate analysis. Receiver Operating Characteristic (ROC) curve was applied to verify the predictive value of the variables in relation to response to treatment, defined by the Area Under the ROC Curve (AUC). Statistical analysis was performed with GraphPad Prismv5.0 (GraphPad Software Inc., La Jolla, CA) and SPSS v.21.0 (SPSS; Chicago, IL).

\section{Results}

\section{HPV infection status and prognosis}

Clinical and pathological features of the Brazilian patients included in this study are presented on Table 1 . Fifty-eight percent (23/40 cases) of the advanced OPSCC were HPV-positive, being HPV16 the most prevalent subtype (19 cases; 1 HPV16/18; 1 HPV16/33; 1 HPV18 and 1 HPV33) (supplementary Table S1). Tonsil was the most common affected site by HPV (57\%) (Table 1). Longer overall survival was observed for HPV-positive compared to HPV-negative cases $(p=0.008$, supplementary Fig. S1A). Risk stratification based on HPV status, smoking history and tumor/node stage [7] was performed. High-risk patients $(n=15)$ showed shorter survival compared with low $(n=15)$ and intermediate-risk patients $(\mathrm{n}=10)(p=0.013$, supplementary Fig. S1B).
Table 1

Patient distribution according to the demographic and clinical variables and $11 \mathrm{q} 13$ amplification status.

\begin{tabular}{|c|c|c|c|}
\hline Characteristics & $\begin{array}{l}\text { Number of patients } \\
\text { (\%), } N=40\end{array}$ & $\begin{array}{l}\text { 11q13 amplification } \\
\text { (\%), } N=33\end{array}$ & $p$ value \\
\hline \multicolumn{4}{|l|}{ Gender } \\
\hline Female & $2(5)$ & $0 / 2(0)$ & \multirow[t]{2}{*}{0.542} \\
\hline Male & $38(95)$ & $11 / 31$ & \\
\hline \multicolumn{4}{|l|}{ Age } \\
\hline $\begin{array}{l}\text { Median (interquartile } \\
\text { range) }\end{array}$ & $55.5(47.8-62.3)$ & & \\
\hline$<60$ years & $26(65)$ & $6 / 20(30)$ & \multirow[t]{2}{*}{0.714} \\
\hline$\geq 60$ years & $14(35)$ & $5 / 13(38.5)$ & \\
\hline \multicolumn{4}{|l|}{ Anatomic site } \\
\hline Base of the tongue & $16(40)$ & 4/14 (28.6) & \multirow[t]{3}{*}{1.000} \\
\hline Soft palate & $1(2.5)$ & & \\
\hline Tonsil & $23(57.5)$ & $6 / 19(31.8)$ & \\
\hline \multicolumn{4}{|l|}{ HPV infection status } \\
\hline Negative & $17(42.5)$ & $7 / 15$ (46.7) & \multirow[t]{4}{*}{0.163} \\
\hline HPV16 & $19(47.5)$ & $4 / 18(22.2)$ & \\
\hline Other HPV $(18 / 33)$ & $2(5)$ & & \\
\hline $\begin{array}{l}\text { Co-infection (HPV16 } \\
\text { and HPV18/33) }\end{array}$ & $2(5)$ & & \\
\hline \multicolumn{4}{|l|}{ Tobacco consumption } \\
\hline No & $9(22.5)$ & $1 / 8(12.5)$ & \multirow[t]{2}{*}{0.218} \\
\hline Yes & $31(77.5)$ & $10 / 25(40)$ & \\
\hline \multicolumn{4}{|l|}{ Alcohol consumption } \\
\hline No & $14(35)$ & $1 / 10(10)$ & \multirow[t]{2}{*}{0.109} \\
\hline Yes & $26(65)$ & $10 / 23(43.5)$ & \\
\hline \multicolumn{4}{|l|}{ Clinical $\mathrm{T}$ stage } \\
\hline $\mathrm{T} 1$ & $1(2.5)$ & $7 / 23(30.4)$ & \multirow[t]{4}{*}{0.696} \\
\hline T2 & 7 (17.5) & & \\
\hline T3 & $21(52.5)$ & & \\
\hline $\mathrm{T} 4$ & $11(27.5)$ & $4 / 10(40)$ & \\
\hline \multicolumn{4}{|l|}{ Clinical N stage } \\
\hline No & $11(27.5)$ & $2 / 9(22.2)$ & \multirow[t]{4}{*}{0.681} \\
\hline N1 & $5(12.5)$ & $9 / 24(37.5)$ & \\
\hline $\mathrm{N} 2$ & $18(45)$ & & \\
\hline N3 & $6(15)$ & & \\
\hline \multicolumn{4}{|l|}{ Stratification risk ${ }^{*}$} \\
\hline Low & $15(37.5)$ & $4 / 20(20)$ & \multirow[t]{3}{*}{0.065} \\
\hline Intermediate & $10(25)$ & & \\
\hline High & $15(37.5)$ & $7 / 13(53.8)$ & \\
\hline \multicolumn{4}{|c|}{ Treatment response $(\mathrm{RXT}+\mathrm{CT})$} \\
\hline $\begin{array}{l}\text { Stable disease/ } \\
\text { progression }\end{array}$ & $3(9.7)$ & $5 / 9(55.6)$ & \multirow[t]{4}{*}{0.097} \\
\hline Partial & $7(22.6)$ & & \\
\hline Complete & $21(67.7)$ & $4 / 19(21.1)$ & \\
\hline Not available $^{\#}$ & 9 & 5 & \\
\hline \multicolumn{4}{|l|}{ Clinical outcome } \\
\hline Free of disease & $25(62.5)$ & $8 / 19(42.1)$ & \multirow[t]{3}{*}{0.278} \\
\hline Local recurrence & $11(27.5)$ & $3 / 14(21.4)$ & \\
\hline Distant Metastasis & $4(10)$ & & \\
\hline \multicolumn{4}{|l|}{ Death } \\
\hline No & $26(65)$ & $5 / 20$ & 0.270 \\
\hline Yes & $14(35)$ & $6 / 13(46.2)$ & \\
\hline
\end{tabular}

* Risk stratification according to Ang et al. [7].

\# Nine patients not submitted to concurrent radiotherapy and chemotherapy (CT-RT).

Amplification in at least one gene located in 11q13; $p$ value: Fisher exact test.

Genomic and transcriptomic analyses in OPSCCs

Fig. 1 summarizes the genomic and transcriptomic analysis approaches and the main results. Recurrent CNAs included losses of 8p11.23-p11.22, 14q11.1-q11.2, 15q11.2 and gains of 11q13.2 and 11q13.2-q13.3. After the comparison of all significant CNA $(p<0.05)$ with DGV database, only gains of 11q13.2 and 11q13.2-q13.3 were 


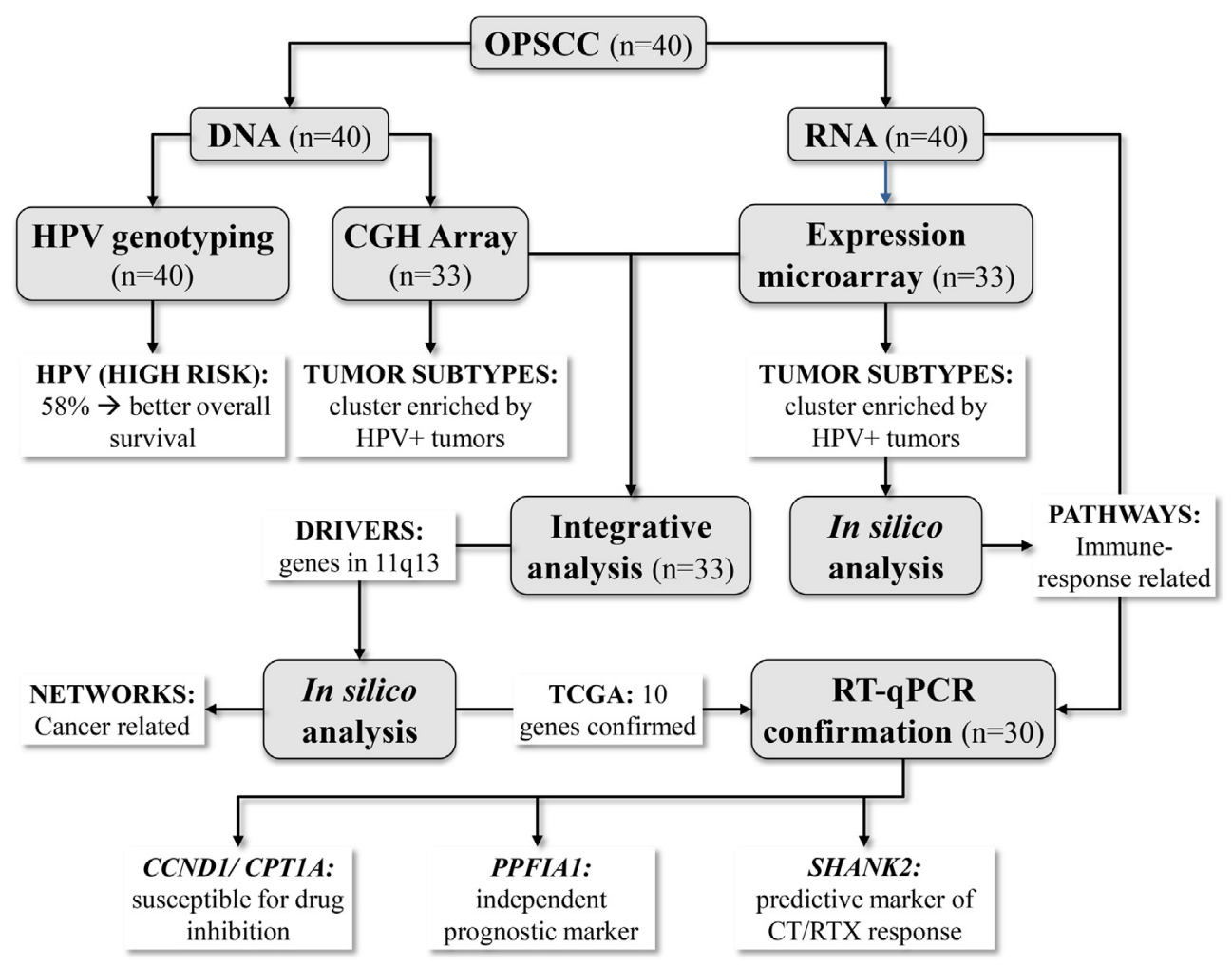

Fig. 1. Flowchart illustrating the methodologies and major findings of the study.

classified as new alterations. Genes and ORFs mapped in these regions are shown in supplementary Table S3.

CNA profiles revealed two clusters of samples, being the cluster 1 enriched by HPV-positive cases (cluster 1: $67 \%$ and cluster 2: $28 \%$, $p=0.038$ ), low/intermediate risk stratification (cluster $1: 77 \%$ and cluster 2: $25 \%, p=0.005$ ), complete chemoradiation response (cluster 1: $89 \%$ and cluster $2: 26 \%, p=0.004$ ) and lower mortality (cluster 1 : $27 \%$ and cluster 2: $82 \%, p=0.008$ ) (Fig. 2A). CNA analysis according to HPV status revealed gains of 3q26.31 and 11q13.2 and losses of 9p21 exclusively detected in HPV-negative cases $(p<0.05$, supplementary Table S4).

The gene expression analysis also demonstrated a cluster of samples enriched by HPV-positive cases (cluster 1: $87 \%$ and cluster 2: $44 \%$, $p=0.027$ ). A trend of low/intermediate risk enrichment (cluster 1 : $85 \%$ and cluster 2: $50 \%, p=0.067$ ) was also observed in the cluster 1 , which presented a partial overlapping with CNA cluster 1 (Fig. 2B). The comparison between these two gene expression clusters revealed 423 differentially expressed transcripts (supplementary Table S5). The pathways identified in HPV-enriched cluster were related to immune response, including interferon-gamma (IFNG) and programmed cell death-1 (PD-1) signaling (supplementary Table S6) (IPA and KOBAS v3.0). The main molecule predicted as activated by IPA upstream regulator analysis was IFNG (supplementary Table S7), which was detected as overexpressed in HPV-enriched cluster.

\section{Integrated genomic and gene expression data}

The integrative analysis using CONEXIC revealed 16 putative modulators mapped at 11q13 (ANO1, CCND1, CPT1A, FADD, FGF3, FGF4, FGF19, IGHMBP2, MRGPRD, MRGPRF, MRPL21, ORAOV1, PPFIA1, PPP6R3, SHANK2 and TPCN2). Ten of 16 modulators showed statistically significant association between copy number gains and higher expression levels (Fig. 3A). Interestingly, copy number gains of these genes were associated with shorter overall survival (Fig. 3B). In silico analysis showed interactions between these 10 driver candidates and their association with cell cycle, cancer, organismal injury and abnormalities (supplementary Fig. S2). In addition, interactions with recognized cancer-related molecules (calmodulin and p21) were observed, being CCND1 and CPT1A susceptible for drug inhibition (arsenic trioxide and perhexiline, respectively) (drugbank: https://www. drugbank.ca/. Accession in February 2018).

\section{Validation of candidate driver genes}

The putative drivers were further tested using the TCGA database of OPSCC, confirming the increased gene expression levels and genomic copy number gains of 10 genes (supplementary Fig. S3A). Similarly to our data, these genomic alterations were also associated with shorter overall survival (supplementary Fig. S3B).

In 30 OPSCC samples with available tissues for RNA extraction RTqPCR confirmed a significant association of genomic gains in 11q13 and overexpression of ORAOV1, CPT1A, PPFIA1 and SHANK2 genes (Fig. 4A). High expression levels of these genes were associated with shorter survival (Fig. 4B). The multivariate analysis revealed PPFIA1 expression and HPV status as independent prognostic markers in advanced OPSCC (Table 2).

Among the four potential markers identified, significant decreased expression level of SHANK2 was detected as predictive marker of complete response (Fig. 4C) and complete response without recurrence in at least five years (Fig. 4D) after concurrent radiotherapy and chemotherapy ( $p=0.010$ and $p=0.012$, respectively). Compared to risk stratification (low, intermediate or high) or HPV status (negative or positive), SHANK2 relative expression presented a higher performance in predicting concurrent CT-RT complete response (AUC $=0.733$, AUC $=0.646$, AUC $=0.833$; respectively) (Fig. 4C) and complete response without recurrence $(\mathrm{AUC}=0.659, \mathrm{AUC}=0.606, \mathrm{AUC}=0.811$; respectively) (Fig. 4D). 
A

\begin{tabular}{|c|}
\hline $\begin{array}{c}\text { Genomic } \\
\text { Profile }\end{array}$ \\
Sample ID
\end{tabular}

Tobacco consumption

Alcohol consumption

HPV infection

T4

High risk*

$\mathrm{CT}^{\#}+\mathrm{RT}$ response

Recurrence

Death
Cluster 1

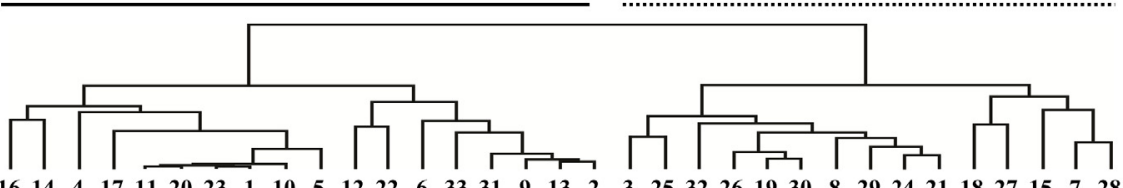

$\begin{array}{lllllllllllllllllllllllllllllllll}16 & 14 & 4 & 17 & 11 & 20 & 23 & 1 & 10 & 5 & 12 & 22 & 6 & 33 & 31 & 9 & 13 & 2 & 3 & 25 & 32 & 26 & 19 & 30 & 8 & 29 & 24 & 21 & 18 & 27 & 15 & 7 & 28\end{array}$
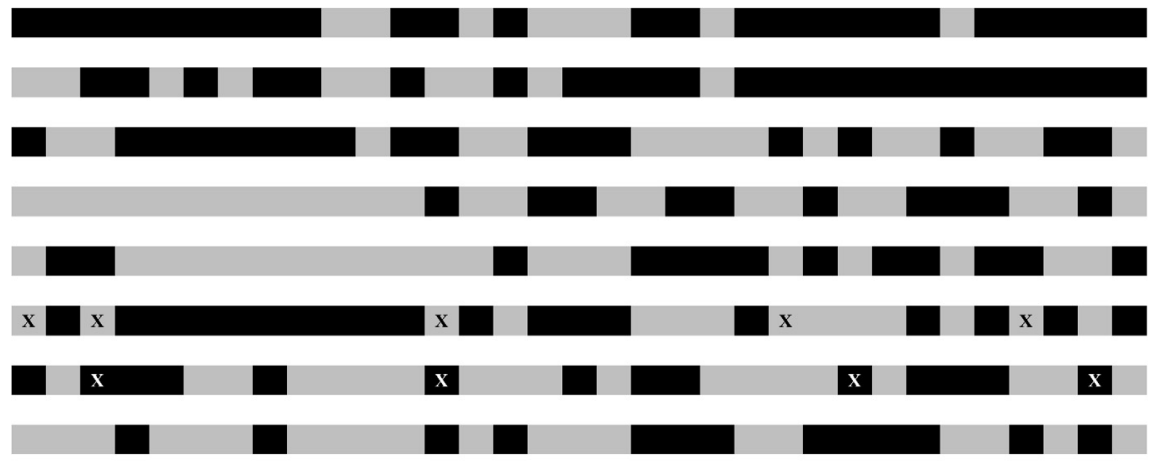

B

\section{Transcriptomic \\ Profile}

Tobacco consumption
Alcohol consumption

HPV infection

T4

High risk*

$\mathrm{CT}^{\#}+\mathrm{RT}$ response

Recurrence

Death
Cluster 1

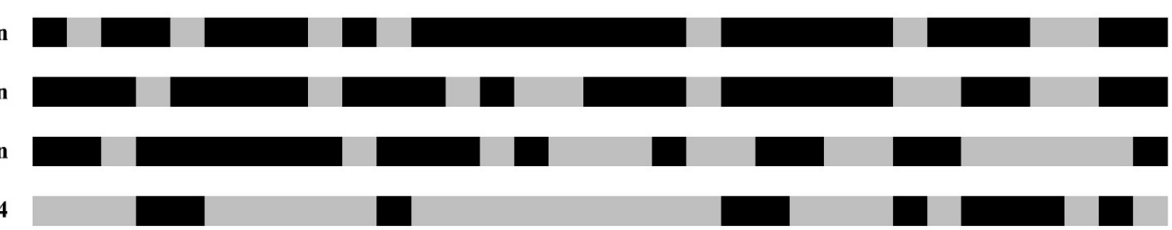

Cluster 2
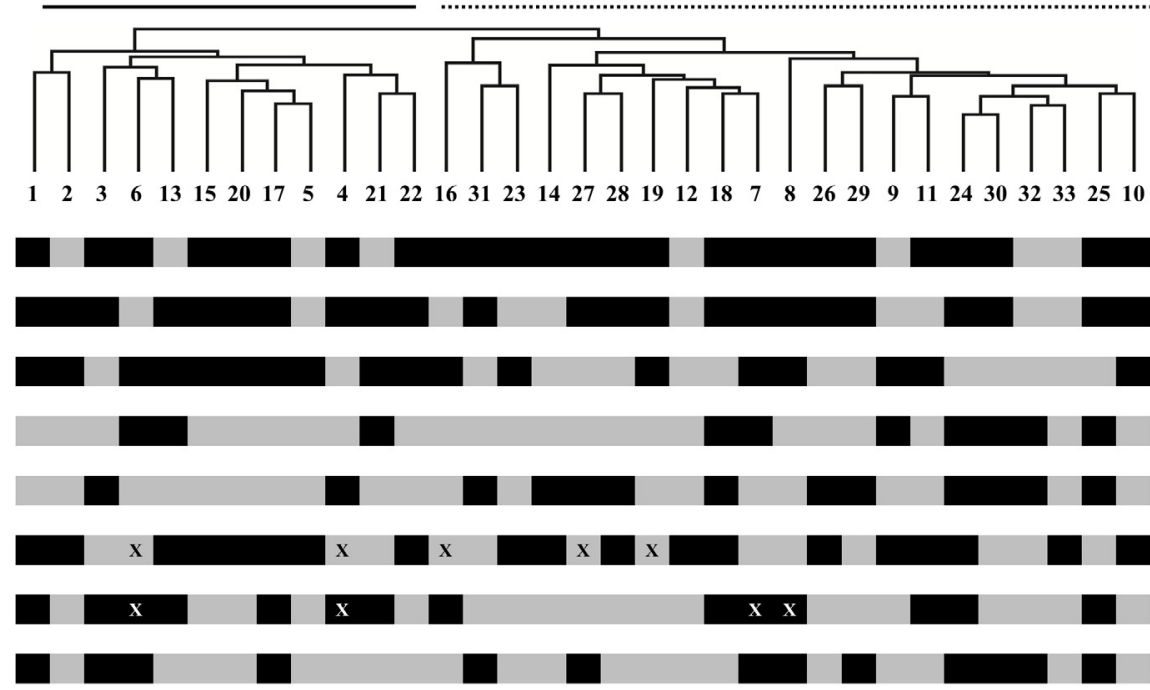

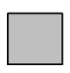

No

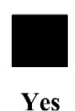

Yes

\section{$\mathrm{x}$}

CT+RT untreated
$\mathbf{X}$

Distant metastasis

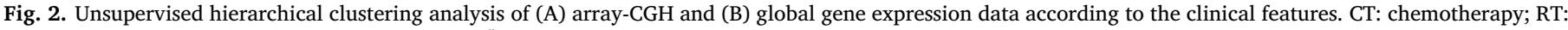

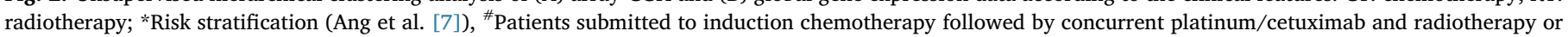
only concurrent platinum/cetuximab and radiotherapy.

\section{Discussion}

This study was designed to reveal potential drivers in locally advanced OPSCC, aiming to identify new therapeutic targets and biomarkers. About half of OPSCC cases were positive for high-risk HPV, which was associated with improved survival, corroborating previous reports $[7,8,10,11,31,32]$. Among the HPV positive cases, 95\% (22/23) were HPV16/18, similar to recent findings described in HNSCC [33]. Moreover, worse prognosis was observed for high-risk patients (according to HPV, TNM and smoking), supporting the hypothesis that the clinical course of HPV-positive tumors is modified by tobacco usage [7]. Curiously, the distribution of HPV infection was uneven between the patient recruitment centers. Tumors collected from Sao Paulo (the largest metropolis in Brazil) presented 77\% (23/30) of positivity compared to $0 \%(0 / 10)$ in the Barretos cohort (an inland city in Brazil southeast). The Brazilian OPSCC patients were recently characterized as having $4 \%$ of HPV positivity compared to $59 \%$ and $31 \%$ in USA and Europe, respectively [34]. However, the predominance of HPV in Brazilian patients can drastically differ due to geographic heterogeneity of our population, which can vary socioeconomically, in alcohol-tobacco consumption and in sexual behavior.

Significant recurrent gains of $11 \mathrm{q}$ and two clusters based on CNA similarities were observed, being the cluster 1 enriched by HPV-positive tumors. Particularly, gains of 11q13.2 (LRP5, PPP6R3 and SAPS3 genes) were exclusively detected in HPV-negative samples. Amplification of $11 \mathrm{q} 13$ is commonly reported in different tumors, including HNSCC $[20,27,35-38]$, particularly in HPV-negative tumors [39,40] and OPSCC [15]. Mutually exclusive amplifications of 11q13 (CCND1 and FADD) and 11q22 (BIRC2 and YAP1) were detected in HPV-negative HNSCC [27]. These data emphasizes that distinct molecular alterations 
A

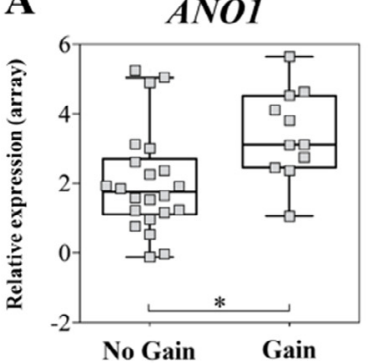

MRPL21

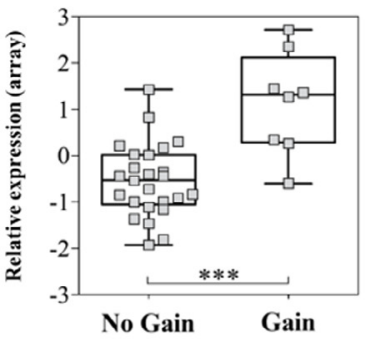

B

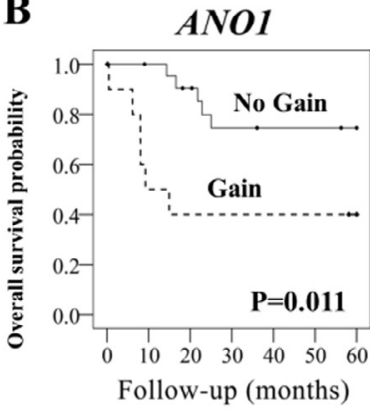

MRPL21

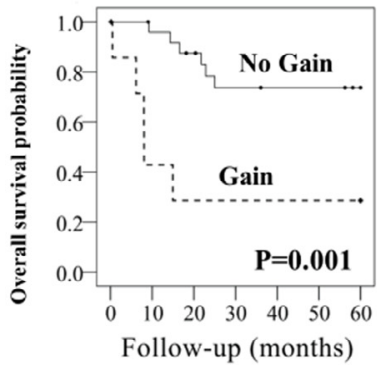

CCND1

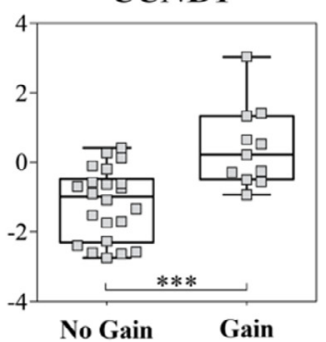

ORAOVI

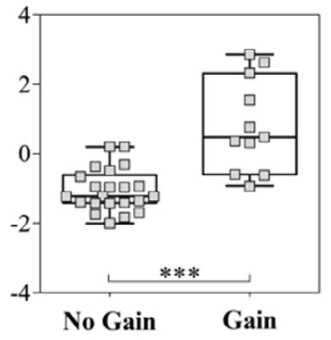

CPT1A

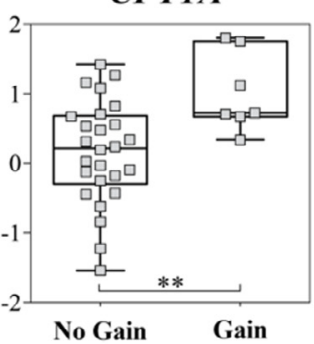

PPFIAI

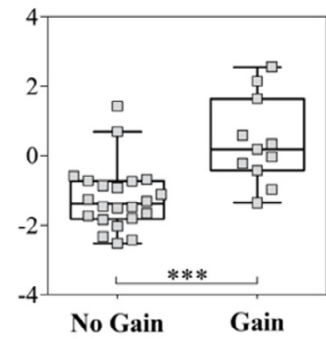

FADD

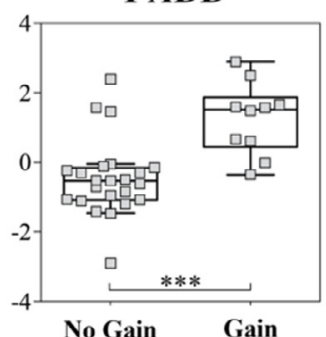

SHANK2

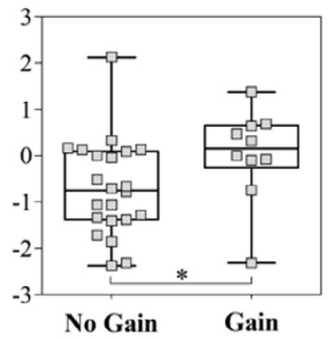

IGHMBP2

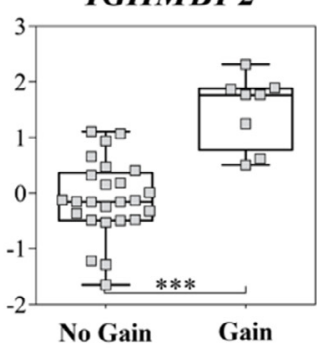

TPCN2

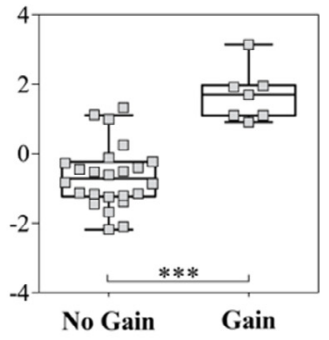

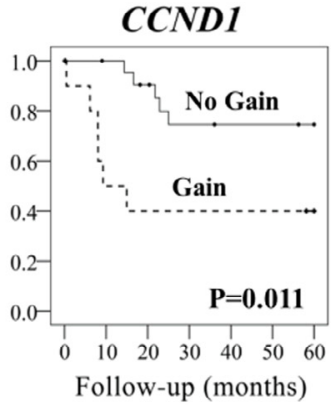
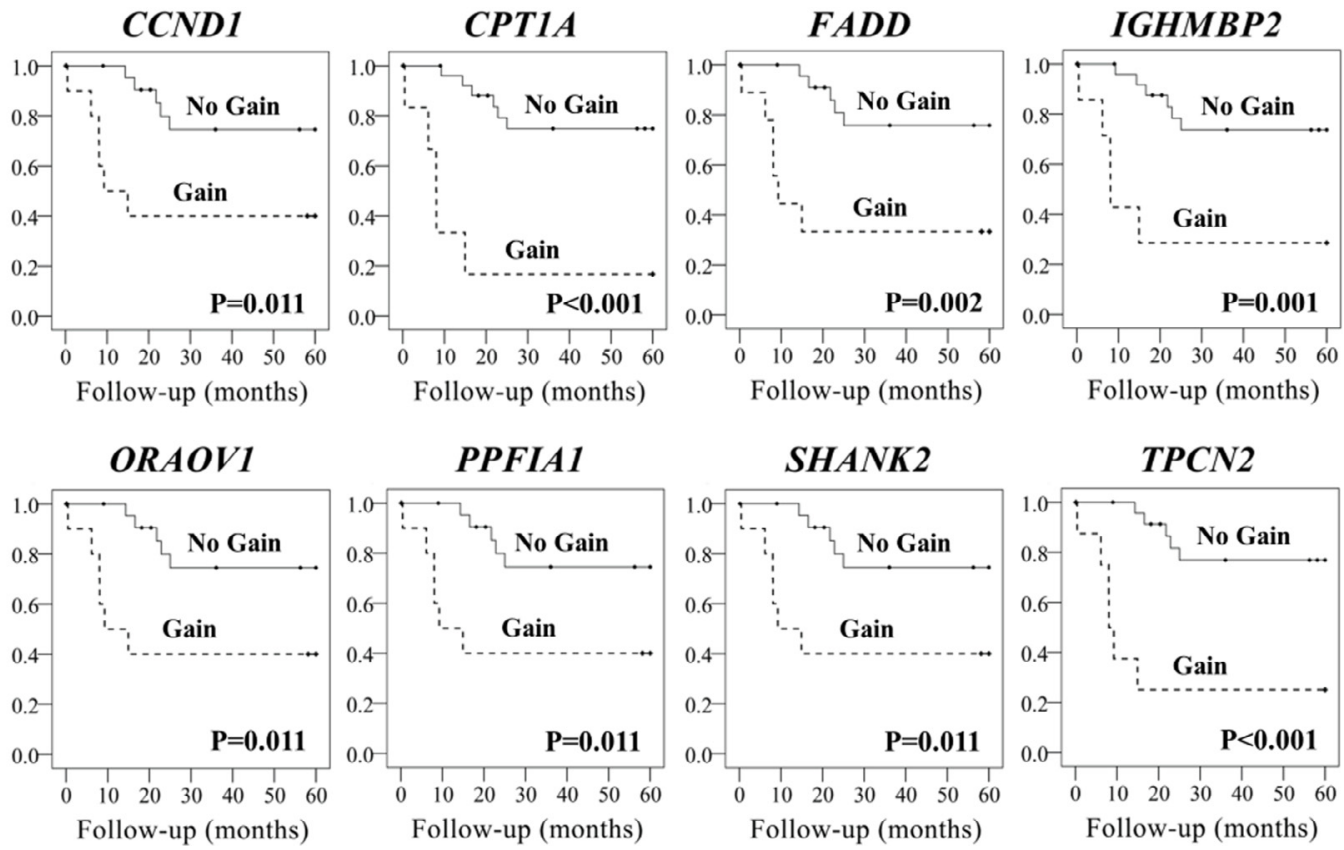

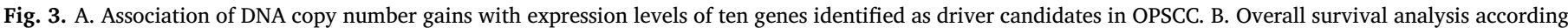

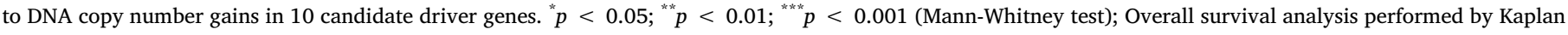
Meyer method with log rank test.

drive the oropharynx carcinogenesis according to the HPV status.

Large-scale gene expression analysis also showed distinct clusters according to HPV status. HPV-enriched cluster presented predominantly immune response-related genes, mainly involving negative regulators of T-cell immune function, as cytotoxic T-lymphocyte-associated antigen 4 (CTLA-4) and programmed death 1 (PD-1) and its ligand PD-L1 immune checkpoints pathway members. The PD-1/PD-L1 and CTLA-4, have shown promising clinical success as a cancer immunotherapy target [41]. Nonetheless, many factors influence in the response to immunotherapies, as the degree of tumor lymphocyte infiltration and the checkpoint proteins levels [13]. A previous study showed that $70 \%$ of HPV-positive HNSCCs presents PD-L1 positive immunostaining [42]. The authors reported increased transcript levels of IFNG in oropharyngeal tumors HPV + /PD-L1 +, suggesting that IFN$\gamma$ might induce PD-L1 in tumor cells. In our study, IFN- $\gamma$ was highly overexpressed in the HPV-positive enriched cluster and was predicted by IPA as the one of the main upstream regulator. Tumor infiltrating lymphocytes overexpressing PD-1 presented better clinical outcome, mostly in head and neck tumors HPV-positives [43]. Furthermore, CD8 + tumor infiltrating lymphocytes showing high expression levels of PD-1 were found more frequently in HPV-negative tumors with compromised IFNG secretion. These patients presented worse prognosis. Conversely, HPV-positive tumors presenting low PD-1 expression in T cells were associated with better response to immunotherapy (anti-PD1) and outcome [43]. In melanoma, the immunostaining positivity for MHC (Major Histocompatibility Complex) class II molecules was 
A

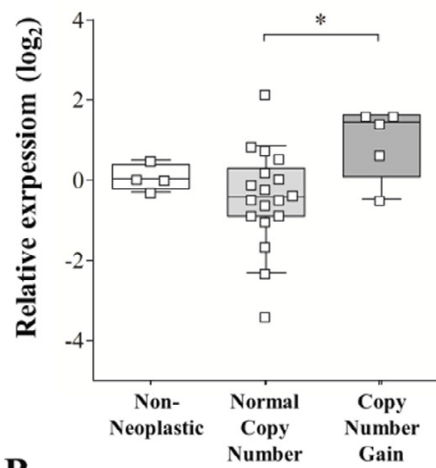

B

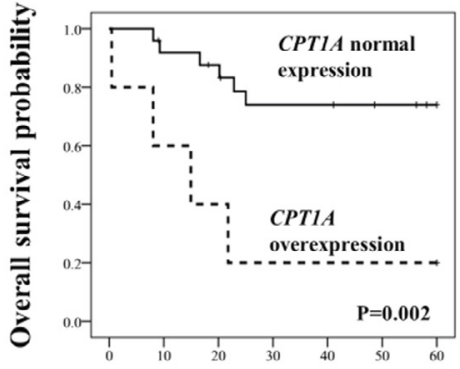

ORAOVI
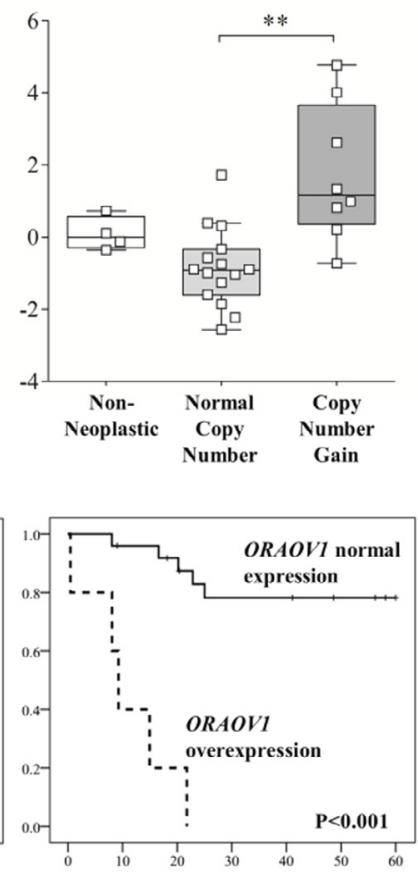

PPFIA1
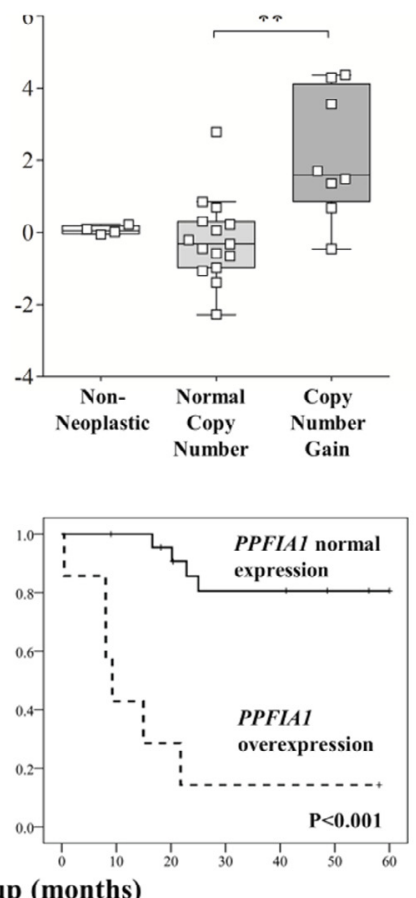

SHANK2
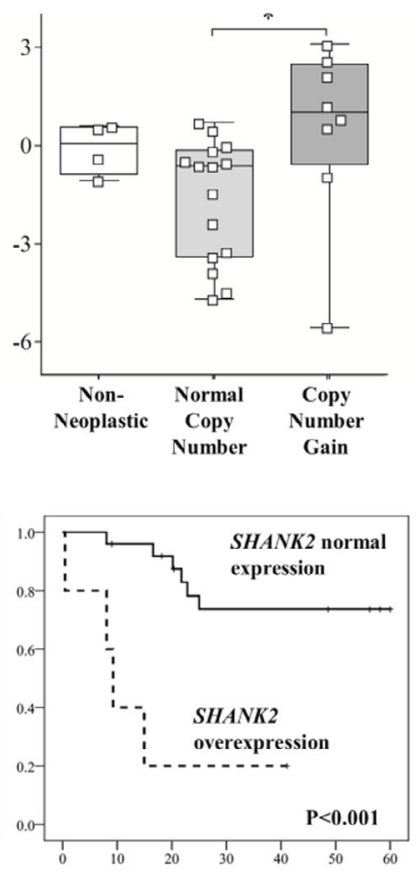

Follow-up (months)

\section{SHANK2 vs. complete CT/RTX response}

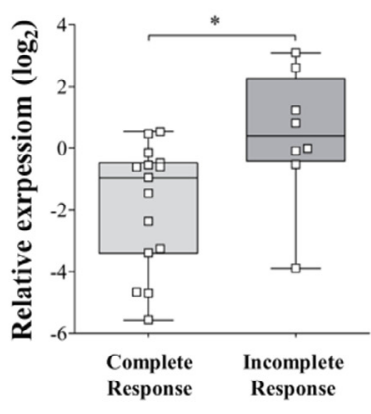

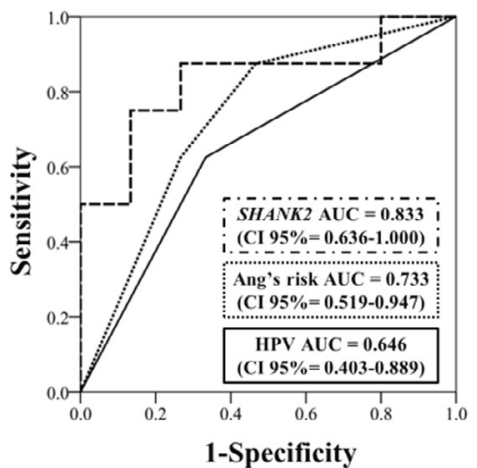

D SHANK2 vs. durable CT/RTX response

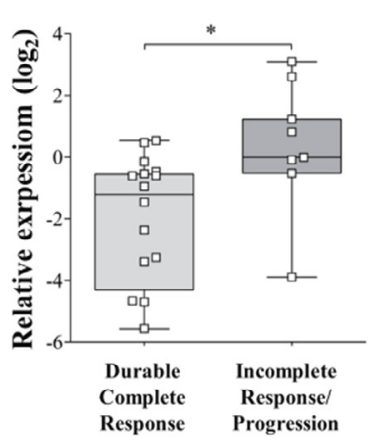

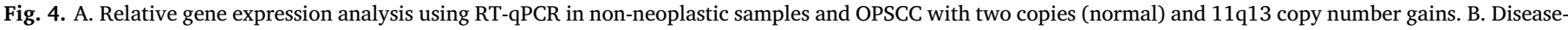

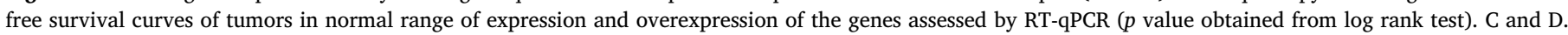

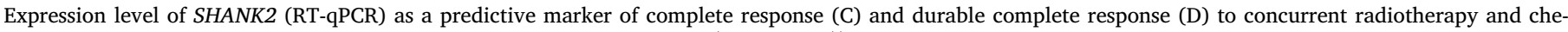

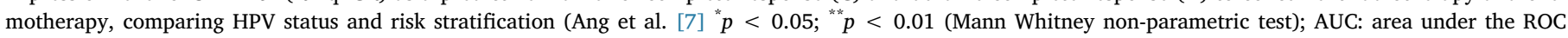
(receiver operating characteristic) curve.

associated with therapeutic response and better clinical outcome in anti-PD-1-treated patients [44]. In our study, overexpression of MHC class II genes was detected in HPV-related cluster (supplementary Table S4). Overall, our findings give additional evidence that PD-1/PD-L1 is a target for new therapeutic strategies in OPSCC, particularly in HPVpositive cases.

Correlation between CNAs mapped in 11q13.2-11q13.3 and corresponding genes expression levels was previously described in HNSCC [21]. In our study, 10 cancer-related genes (ANO1, CCND1, CPT1A, FADD, IGHMBP2, MRPL21, ORAOV1, PPFIA1, SHANK2 and TPCN2) mapped in 11q13 showed copy number gains and overexpression. These findings were further validated using the TCGA, suggesting that other genes besides CCND1 may confer an advantage to OPSCC cells [45]. Moreover, gains involving these genes were associated with worse survival in our study and in TCGA, thus supporting their relevance in
OPSCC outcomes.

Further analysis using RT-qPCR confirmed an association among ORAOV1, CPT1A, PPFIA1 and SHANK2 overexpression and shorter survival. A meta-analysis comprising 15 publically available microarray gene expression data assessing 140 normal and 277 HNSCC samples revealed a list of 181 differentially expressed genes. ANO1 and FADD (both mapped in 11q13) were overexpressed in at least $30 \%$ of the TCGA samples (528 HNSCC), and associated with higher risk of recurrence and death [46]. Gains of 11q13.2, including CPT1A, were also associated with worse survival in patients with esophageal carcinoma [47]. CPT1A (Carnitine palmitoyl transferase 1A) gene encodes a ratelimiting enzyme for fatty acid transport inside the mitochondria for $\beta$ oxidation. Fatty acid oxidation is essential for ATP production in metabolic stress conditions and particularly in cancer [48]. Enzymes involved in fatty acid oxidation, such as CPT1, are promising targets for 
Table 2

Univariate and multivariate analysis of OPSCC overall survival.

\begin{tabular}{|c|c|c|c|c|}
\hline \multirow[t]{2}{*}{ Variables } & \multicolumn{2}{|c|}{ Univariate analysis } & \multicolumn{2}{|c|}{ Multivariate analysis } \\
\hline & $\mathrm{HR}\left(\mathrm{CI}_{95 \%}\right)$ & $p$ value & $\mathrm{HR}\left(\mathrm{CI}_{95 \%}\right)$ & $p$ value \\
\hline \multicolumn{5}{|l|}{ HPV infection } \\
\hline No & 1 & & 1 & \\
\hline Yes & $0.3(0.1-1)$ & 0.056 & $0.1(0.02-0.56)$ & 0.001 \\
\hline \multicolumn{5}{|l|}{ Ang's risk stratification } \\
\hline Low/Intermediate & 1 & & & \\
\hline High & $3.7(1-14.5)$ & 0.056 & - & - \\
\hline \multicolumn{5}{|l|}{ CPT1A expression } \\
\hline Normal range & 1 & & & \\
\hline Overexpression & $6(1.7-21.9)$ & 0.006 & - & - \\
\hline \multicolumn{5}{|l|}{ ORAOV1 expression } \\
\hline Normal range & 1 & & & \\
\hline Overexpression & $18.3(4.1-80.9)$ & $<0.001$ & - & - \\
\hline \multicolumn{5}{|l|}{ PPFIA1 expression } \\
\hline Normal range & 1 & & 1 & \\
\hline Overexpression & $11.9(3.2-44.1)$ & $<0.001$ & $30.9(5.3-179.6)$ & $<0.001$ \\
\hline \multicolumn{5}{|l|}{ SHANK2 expression } \\
\hline Normal range & 1 & & & \\
\hline Overexpression & $7.6(2-28.1)$ & 0.003 & - & - \\
\hline
\end{tabular}

HR: hazard ratio; $\mathrm{CI}_{95 \%}$ : confidence interval of $95 \%$. $p$ value: Cox proportionalhazards regression.

cancer therapy [48] and might be considered as a potential target in OPSCC. Interestingly, CPT1 enzyme can be pharmacologically inhibited by perhexiline [49].

Although increased expression levels of ORAOV1 (oral cancer overexpressed 1) have been reported in several tumors [50-52], its biological function is not completely characterized. In oral carcinomas, reduced ORAOV1 expression was associated with delayed cell growth in vitro and inhibition of tumor growth and angiogenesis in vivo [51]. A protective response to reactive oxygen species was related to ORAOV1 overexpression, a common feature of many cancers [53], including HNSCC [54]. Despite the small sample size and number of events (10 patients died during a 5-year follow-up), PPFIA1 overexpression was identified as an independent prognostic marker (independent of the HPV status and/or tobacco consumption). PPFIA1 was reported as the highest up-regulated gene associated with copy number gains of 11q13 in HNSCC cell lines [55]. In breast cancer cells, the silencing of PPFIA1 promotes inhibition of migration and invasion [56]. Overall, our data suggest that PPFIA1 acts as an oncogene in OPSCC, although its function in these tumors requires further studies.

SHANK2 overexpression was associated with incomplete response to therapy, being able to distinguish treatment-unresponsive from responsive tumors more efficiently than HPV status. SHANK2 is a member of scaffold protein family involved in excitatory synapses in the central nervous system. In oral carcinomas, co-amplification and overexpression of SHANK2 and CTTN was reported, suggesting a cooperative role of these proteins on tumor cell motility and invasiveness [57]. Amplification and overexpression of SHANK2 was also associated with poor prognosis in esophageal squamous cell carcinoma [58]. In oral carcinomas, SHANK2 was described as one of seven prognostic markers evaluated by DNA methylation [59]. These finding suggest that CNA and/or epigenetic mechanisms may result in SHANK2 increased expression and consequent HNSCC aggressiveness. To our knowledge, the association between genes mapped in 11q13 and chemoradiation response was not previously reported. The role of these genes in oropharyngeal carcinogenesis, particularly in tumor aggressiveness and their ability to predict therapy response, should be further investigated.

Considering that only locally advanced OPSCC biopsies obtained from patients subsequently treated with specific therapeutic strategies were included in our study, the major limitation was the small sample size $(n=40)$. Nonetheless, with the addition of an independent sample set $(n=78)$ from TCGA (not treatment-standardized), we were able to confirm the potential clinical relevance of genes mapped in 11q13.

In conclusion, we described a higher frequency of HPV infection than previous Brazilian OPSCC reports, which varied greatly according to the geographic region and tobacco-alcohol consumption. HPV-positive tumors showed an immune response-related gene signature, which can have an impact on immunotherapy response prediction leading to a more precise treatment indication. In addition to CCND1 previously described, novel driver genes including ORAOV1, CPT1A, PPFIA1 and SHANK2 genes mapped in 11q13 presented a role in the prognosis and chemoradiation response prediction, regardless of the HPV status.

\section{Conflict of interest statement}

None declared.

\section{Acknowledgments}

The authors would like to thank the Macromolecules Laboratory at the A.C. Camargo Cancer Center and Barretos Cancer Hospital. This study was supported by grants from the National Institute of Science and Technology in Oncogenomics (FAPESP \#2008/57887-9 and CNPq \#573589/08-9).

\section{Authors' contributions}

SRR and LPK conceived and designed the experiments; MCBF, MH and LARR conducted the experiments; MCBF, FAM, LARR, SAD analyzed the data; SRR and LPK contributed with reagents/materials; SRR, LPK and SAD supervised the study; CALP performed the histopathological evaluation; URN, ALC and LPK selected the cases and obtained the clinical data; MCBF, SAD and SRR wrote and edited the manuscript. All authors read and approved the final version of the manuscript.

\section{Appendix A. Supplementary data}

Supplementary data associated with this article can be found, in the online version, at https://doi.org/10.1016/j.oraloncology.2018.06. 010 .

\section{References}

[1] Chaturvedi AK, Anderson WF, Lortet-Tieulent J, Curado MP, Ferlay J, Franceschi S, et al. Worldwide trends in incidence rates for oral cavity and oropharyngeal cancers. J Clin Oncol 2013;31:4550-9. http://dx.doi.org/10.1200/JCO.2013.50.3870.

[2] Panwar A, Batra R, Lydiatt WM, Ganti AK. Human papilloma virus positive oropharyngeal squamous cell carcinoma: a growing epidemic. Cancer Treat Rev 2014;40:215-9. http://dx.doi.org/10.1016/j.ctrv.2013.09.006.

[3] Simard EP, Torre LA, Jemal A. International trends in head and neck cancer incidence rates: differences by country, sex and anatomic site. Oral Oncol 2014;50:387-403. http://dx.doi.org/10.1016/j.oraloncology.2014.01.016.

[4] D'Souza G, Westra WH, Wang SJ, van Zante A, Wentz A, Kluz N, et al. Differences in the prevalence of Human Papillomavirus (HPV) in head and neck squamous cell cancers by sex, race, anatomic tumor site, and HPV detection method. JAMA Oncol 2016:169-77. http://dx.doi.org/10.1001/jamaoncol.2016.3067.

[5] Hussein AA, Helder MN, de Visscher JG, Leemans CR, Braakhuis BJ, de Vet HCW, et al. Global incidence of oral and oropharynx cancer in patients younger than 45 years versus older patients: a systematic review. Eur J Cancer 2017;82:115-27. http://dx.doi.org/10.1016/j.ejca.2017.05.026.

[6] Shield KD, Ferlay J, Jemal A, Sankaranarayanan R, Chaturvedi AK, Bray F, et al. The global incidence of lip, oral cavity, and pharyngeal cancers by subsite in 2012. CA Cancer J Clin 2017;67:51-64. http://dx.doi.org/10.3322/caac.21384.

[7] Ang KK, Harris J, Wheeler R, Weber R, Rosenthal DI, Nguyen-Tân PF, et al. Human papillomavirus and survival of patients with oropharyngeal cancer. $\mathrm{N}$ Engl $\mathrm{J}$ Med 2010;363:24-35. http://dx.doi.org/10.1056/NEJMoa0912217.

[8] Psyrri A, Rampias T, Vermorken JB. The current and future impact of human papillomavirus on treatment of squamous cell carcinoma of the head and neck. Ann Oncol 2014;25:2101-15. http://dx.doi.org/10.1093/annonc/mdu265.

[9] Urban D, Corry J, Rischin D. What is the best treatment for patients with human papillomavirus-positive and -negative oropharyngeal cancer? Cancer 2014;120:1462-70. http://dx.doi.org/10.1002/cncr.28595. 
[10] Fakhry C, Westra WH, Wang SJ, van Zante A, Zhang Y, Rettig E, et al. The prognostic role of sex, race, and human papillomavirus in oropharyngeal and nonoropharyngeal head and neck squamous cell cancer. Cancer 2017;123:1566-75. http://dx.doi.org/10.1002/cncr.30353.

[11] Lacau St Guily J, Rousseau A, Baujat B, Périé S, Schultz P, Barry B, et al. Papillophar group. Oropharyngeal cancer prognosis by tumor HPV status in France: the multicentric Papillophar study. Oral Oncol 2017;67:29-36. http://dx.doi.org/10.1016/ j.oraloncology.2017.01.012.

[12] Chera BS, Amdur RJ. Current status and future directions of treatment deintensification in human papilloma virus-associated oropharyngeal squamous cell carcinoma. Semin Radiat Oncol 2018;28:27-34. http://dx.doi.org/10.1016/j semradonc.2017.08.001.

[13] Leemans CR, Snijders PJF, Brakenhoff RH. The molecular landscape of head and neck cancer. Nat Rev Cancer 2018. http://dx.doi.org/10.1038/nrc.2018.11.

[14] O'Sullivan B, Huang SH, Siu LL, Waldron J, Zhao H, Perez-Ordonez B, et al. Deintensification candidate subgroups in human papillomavirus-related oropharyngeal cancer according to minimal risk of distant metastasis. J Clin Oncol 2013;31:543-50. http://dx.doi.org/10.1200/JCO.2012.44.0164.

[15] Klussmann JP, Mooren JJ, Lehnen M, Claessen SM, Stenner M, Huebbers CU, et al. Genetic signatures of HPV-related and unrelated oropharyngeal carcinoma and their prognostic implications. Clin Cancer Res 2009;15:1779-86. http://dx.doi.org/ 10.1158/1078-0432.CCR-08-1463.

[16] Jung AC, Briolat J, Millon R, de Reyniès A, Rickman D, Thomas E, et al. Biological and clinical relevance of transcriptionally active human papillomavirus (HPV) infection in oropharynx squamous cell carcinoma. Int J Cancer 2010;126:1882-94. http://dx.doi.org/10.1002/ijc.24911.

[17] Kang H, Kiess A, Chung CH. Emerging biomarkers in head and neck cancer in the era of genomics. Nat Rev Clin Oncol 2015;12:11-26. http://dx.doi.org/10.1038/ nrclinonc.2014.192.

[18] Papillon-Cavanagh S, Lu C, Gayden T, Mikael LG, Bechet D, Karamboulas C, et al. Impaired H3K36 methylation defines a subset of head and neck squamous cell carcinomas. Nat Genet 2017;49:180-5. http://dx.doi.org/10.1038/ng.3757.

[19] Boscolo-Rizzo P, Furlan C, Lupato V, Polesel J, Fratta E. Novel insights into epigenetic drivers of oropharyngeal squamous cell carcinoma: role of HPV and lifestyle factors. Clin Epigenetics 2017;109:24. http://dx.doi.org/10.1186/s13148-0170424-5.

[20] Pickering CR, Zhang J, Yoo SY, Bengtsson L, Moorthy S, Neskey DM, et al. Integrative genomic characterization of oral squamous cell carcinoma identifie frequent somatic drivers. Cancer Discov 2013;3:770-81. http://dx.doi.org/10. 1158/2159-8290.CD-12-0537.

[21] Xu C, Liu Y, Wang P, Fan W, Rue TC, Upton MP, et al. Integrative analysis of DNA copy number and gene expression in metastatic oral squamous cell carcinoma identifies genes associated with poor survival. Mol Cancer 2010;9:143-54. http:// dx.doi.org/10.1186/1476-4598-9-143.

[22] Etemadmoghadam D, deFazio A, Beroukhim R, Mermel C, George J, Getz G, et al. AOCS Study Group. Integrated genome-wide DNA copy number and expression analysis identifies distinct mechanisms of primary chemoresistance in ovarian carcinomas. Clin Cancer Res 2009;15:1417-27. http://dx.doi.org/10.1158/1078 0432. CCR-08-1564.

[23] Busso-Lopez AF, Marchi FA, Kuasne H, Scapulatempo-Neto C, Trindade-Filho JC, de Jesus CM, et al. Genomic profiling of human penile carcinoma predicts worse prognosis and survival. Cancer Prev Res (Phila) 2015;8:149-56. http://dx.doi.org/ 10.1158/1940-6207.CAPR-14-0284.

[24] Marchi FA, Martins DC, Barros-Filho MC, Kuasne H, Busso Lopes AF, Brentani H, et al. Multidimensional integrative analysis uncovers driver candidates and biomarkers in penile carcinoma. Sci Rep 2017;7:6707-17. http://dx.doi.org/10.1038/ s41598-017-06659-1.

[25] Cirilo PD, Marchi FA, Barros Filho Mde C, Rocha RM, Domingues MA, Jurisica I, et al. An integrative genomic and transcriptomic analysis reveals potential targets associated with cell proliferation in uterine leiomyomas. PLoS One 2013;8:e57901. http://dx.doi.org/10.1371/journal.pone.0057901.

[26] Chudasama P, Mughal SS, Sanders MA, Hübschmann D, Chung I, Deeg KI, et al. Integrative genomic and transcriptomic analysis of leiomyosarcoma. Nat Commun. 2018;9:144. http://dx.doi.org/10.1038/s41467-017-02602-0.

[27] Cancer Genome Atlas Network. Comprehensive genomic characterization of head and neck squamous cell carcinomas. Nature 2015;517:576-82. http://dx.doi.org/ 10.1038/nature14129.

[28] Akavia UD, Litvin O, Kim J, Sanchez-Garcia F, Kotliar D, Causton HC, et al. An integrated approach to uncover drivers of cancer. Cell 2010;143:1005-17. http:// dx.doi.org/10.1016/j.cell.2010.11.013.

[29] Vandesompele J, De Preter K, Pattyn F, Poppe B, Van Roy N, De Paepe A, et al. Accurate normalization of real-time quantitative RT-PCR data by geometric averaging of multiple internal control genes. Genome Biol 2002;3. RESEARCH0034.

[30] Pfaffl MW. A new mathematical model for relative quantification in real-time RT PCR. Nucleic Acids Res 2001;29:e45.

[31] Lindel K, Beer KT, Laissue J, Greiner RH, Aebersold DM. Human Papillomavirus positive squamous cell carcinoma of the oropharynx. A radiosensitive subgroup of head and neck carcinoma. Cancer 2001;92:805-13.

[32] Fischer CA, Zlobec I, Green E, Probst S, Storck C, Lugli A, et al. Is the improved prognosis of p16 positive oropharyngeal squamous cell carcinoma dependent of the treatment modality? Int J Cancer 2010;126:1256-62. http://dx.doi.org/10.1002/ ijc. 24842 .

33] de Martel C, Plummer M, Vignat J, Franceschi S. Worldwide burden of cancer attributable to HPV by site, country and HPV type. Int J Cancer 2017;141:664-70. http://dx.doi.org/10.1002/ijc.30716.

34] Anantharaman D, Abedi-Ardekani B, Beachler DC, Gheit T, Olshan AF, Wisniewski
$\mathrm{K}$, et al. Geographic heterogeneity in the prevalence of human papillomavirus in head and neck cancer. Int J Cancer 2017;140:1968-75. http://dx.doi.org/10.1002/ ijc.30608.

[35] Meredith SD, Levine PA, Burns JA, Gaffey MJ, Boyd JC, Weiss LM, et al. Chromosome 11q13 amplification in head and neck squamous cell carcinoma. Association with poor prognosis. Arch Otolaryngol Head Neck Surg 1995;121:790-4.

[36] Ambatipudi S, Gerstung M, Gowda R, Pai P, Borges AM, Schäffer AA, et al. Genomic profiling of advanced-stage oral cancers reveals chromosome $11 \mathrm{q}$ alterations as markers of poor clinical outcome. PLoS One 2011;6:e17250. http://dx.doi.org/10. 1371/journal.pone.0017250.

[37] Ambrosio EP, Silveira CG, Drigo SA, Sacomano Vde S, Molck MC, Rocha RM, et al. Chromosomal imbalances exclusively detected in invasive front area are associated with poor outcome in laryngeal carcinomas from different anatomical sites. Tumor Biol 2013;34:3015-26. http://dx.doi.org/10.1007/s13277-013-0866-0.

[38] Morris LG, Chandramohan R, West L, Zehir A, Chakravarty D, Pfister DG, et al. The molecular landscape of recurrent and metastatic head and neck cancers: insights from a precision oncology sequencing platform. JAMA Oncol 2017;3:244-55. http://dx.doi.org/10.1001/jamaoncol.2016.1790.

[39] Ragin CC, Taioli E, Weissfeld JL, White JS, Rossie KM, Modugno F, et al. 11q13 amplification status and human papillomavirus in relation to p16 expression defines two distinct etiologies of head and neck tumors. Br J Cancer 2006;95:1432-8.

[40] Seiwert TY, Zuo Z, Keck MK, Khattri A, Pedamallu CS, Stricker T, et al. Integrative and comparative genomic analysis of HPV-positive and HPV-negative head and neck squamous cell carcinomas. Clin Cancer Res 2015;21:632-41. http://dx.doi org/10.1158/1078-0432.CCR-13-3310.

[41] Gotwals P, Cameron S, Cipolletta D, Cremasco V, Crystal A, Hewes B, et al. Prospects for combining targeted and conventional cancer therapy with immunotherapy. Nat Rev Cancer 2017;17:286-301. http://dx.doi.org/10.1038/nrc 2017.17.

[42] Lyford-Pike S, Peng S, Young GD, Taube JM, Westra WH, Akpeng B, et al. Evidence for a role of the PD-1:PD-L1 pathway in immune resistance of HPV-associated head and neck squamous cell carcinoma. Cancer Res 2013;73:1733-41. http://dx.doi. org $/ 10.1158 / 0008-5472$.CAN-12-2384

[43] Kansy BA, Concha-Benavente F, Srivastava RM, Jie HB, Shayan G, Lei Y, et al. PD-1 Status in CD8 $(+)$ T Cells associates with survival and anti-PD-1 therapeutic outcomes in head and neck cancer. Cancer Res 2017;77:6353-64. http://dx.doi.org/ 10.1158/0008-5472. CAN-16-3167.

[44] Johnson DB, Estrada MV, Salgado R, Sanchez V, Doxie DB, Opalenik SR, et al Melanoma-specific MHC-II expression represents a tumor-autonomous phenotype and predicts response to anti-PD-1/PD-L1 therapy. Nat Commun 2016;7:10582. http://dx.doi.org/10.1038/ncomms10582.

[45] Wilkerson PM, Reis-Filho JS. The 11q13-q14 amplicon: clinicopathological correlations and potential drivers. Genes Chromosomes Cancer 2013;52:333-55. http:// dx.doi.org/10.1002/gcc.22037.

[46] Reddy RB, Bhat AR, James BL, Govindan SV, Mathew R, Ravindra DR, et al. Metaanalyses of microarray datasets identifies ANO1 and FADD as prognostic markers of head and neck cancer. PLoS One 2016;11:e0147409. http://dx.doi.org/10.1371/ journal.pone.0147409.

[47] Shi ZZ, Liang JW, Zhan T, Wang BS, Lin DC, Liu SG, et al. Genomic alterations with impact on survival in esophageal squamous cell carcinoma identified by array comparative genomic hybridization. Genes Chromosomes Cancer 2011;50:518-26. http://dx.doi.org/10.1002/gcc.20875.

[48] Carracedo A, Cantley LC, Pandolfi PP. Cancer metabolism: fatty acid oxidation in the limelight. Nat Rev Cancer 2013;13:227-32. http://dx.doi.org/10.1038/ nrc3483.

[49] Kennedy JA, Unger SA, Horowitz JD. Inhibition of carnitine palmitoyltransferase-1 in rat heart and liver by perhexiline and amiodarone. Biochem Pharmaco 1996;52:273-80.

[50] Jiang L, Zeng X, Wang Z, Ji N, Zhou Y, Liu X, et al. Oral cancer overexpressed (ORAOV1) regulates cell cycle and apoptosis in cervical cancer HeLa cells. Mol Cancer 2010;9:20. http://dx doi.org/10.1186/1476-4598-9-20.

[51] Jiang L, Zeng X, Yang H, Wang Z, Shen J, Bai J, et al. Oral cancer overexpressed 1 (ORAOV1): a regulator for the cell growth and tumor angiogenesis in oral squamous cell carcinoma. Int J Cancer 2008;123:1779-86. http://dx.doi.org/10.1002/ijc. 23734

[52] Li M, Cui X, Shen Y, Dong H, Liang W, Chen Y, et al. ORAOV1 overexpression in esophageal squamous cell carcinoma and esophageal dysplasia: a possible biomarker of progression and poor prognosis in esophageal carcinoma. Hum Pathol 2015;46:707-15. http://dx.doi.org/10.1016/j.humpath.2015.01.009.

[53] Zhai C, Li Y, Mascarenhas C, Lin Q, Li K, Vyrides I, et al. The function of ORAOV1/ LTO1, a gene that is overexpressed frequently in cancer: essential roles in the function and biogenesis of the ribosome. Oncogene 2014;33:484-94. http://dx.doi. org/10.1038/onc.2012.604.

[54] Choudhari SK, Chaudhary M, Gadbail AR, Sharma A, Tekade S. Oxidative and antioxidative mechanisms in oral cancer and precancer: a review. Oral Oncol 2014;50:10-8. http://dx.doi.org/10.1016/j.oraloncology.2013.09.011.

[55] Tan KD, Zhu Y, Tan HK, Rajasegaran V, Aggarwal A, Wu J, et al. Amplification and overexpression of PPFIA1, a putative 11q13 invasion and suppressor gene, in head and neck squamous cell carcinoma. Genes Chromosomes Cancer 2008;47:353-62. http://dx.doi.org/10.1002/gcc.20539.

[56] Astro V, Asperti C, Cangi MG, Doglioni C, de Curtis I. Liprin- $\alpha 1$ regulates breast cancer cell invasion by affecting cell motility, invadopodia and extracellular matrix degradation. Oncogene 2011;30:1841-9. http://dx.doi.org/10.1038/onc.2010.562.

[57] Freier K, Sticht C, Hofele C, Flechtenmacher C, Stange D, Puccio L, et al. Recurren coamplification of cytoskeleton-associated genes EMS1 and SHANK2 with CCND1 
in oral squamous cell carcinoma. Genes Chromosomes Cancer 2006;45:118-25.

[58] Qin HD, Liao XY, Chen YB, Huang SY, Xue WQ, Li FF, et al. Genomic characterization of esophageal squamous cell carcinoma reveals critical genes underlying tumorigenesis and poor prognosis. Am J Hum Genet 2016;98:709-27. http://dx. doi.org/10.1016/j.ajhg.2016.02.021.
[59] Shen S, Wang G, Shi Q, Zhang R, Zhao Y, Wei Y, et al. Seven-CpG-based prognostic signature coupled with gene expression predicts survival of oral squamous cell carcinoma. Clin Epigenetics 2017;9:88-98. http://dx.doi.org/10.1186/s13148017-0392-9. 